\title{
SOBRE A NATUREZA, DE PARMÊNIDES DE ELEIA ${ }^{1}$
}

RESUMO: Ofereço uma tradução poética da obra Sobre a natureza, de

\author{
Pedro Barbieri* \\ Recebido em: 14/10/2019 \\ Aprovado em: 07/01/2020
}

Parmênides.

PALAVRAS-CHAVE: Parmênides; Sobre a naturez̧a; poesia hexamétrica; tradução poética.

\section{PARMENIDES OF ELEA'S ON NATURE}

ABSTRACT: I offer a full poetic translation of Parmenides' fragmentary On Nature.

KEYWORDS: Parmenides; On Nature; hexametric poetry; poetic translation.

\section{BREVE Nota À TRAduÇão}

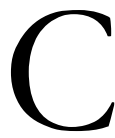

omo é sabido na área tradutológica, em especial aquela que lida com textos clássicos, há muitas possibilidades de abordarmos o traslado de um texto antigo qualquer, em especial de um texto poético. Podemos optar por uma tradução escolar ou pedagógica, que não se detém sobre a formalidade do texto e o trata principalmente como um "conteúdo" a ser assimilado, um enredo ou uma exposição de ideias. Assim, no espectro da palatabilidade do texto, ele pode ser traduzido em prosa, sob a égide da descrença quanto à recriação da poeticidade original; ou, em uma espécie de meio termo, uma obra em versos pode ser traduzida justamente como um poema, porém quase como uma prosa recortada, apenas com a equivalência entre o verso original e

\footnotetext{
${ }^{1}$ Agradeço os comentários feitos pelos pareceristas anônimos. Todos os deslizes remanescentes são de minha autoria.
}

* Doutorando do Programa de PósGraduação em Letras Clássicas, Faculdade de Filosofia, Letras e Ciências Humanas, Universidade de São Paulo. pedrobarbieri.antunes@ gmail.com 
o vernáculo. A tradução propriamente poética, por sua vez, opta por lidar com um poema tal qual ele é, levando em consideração aspectos formais, rítmicos, estruturais, buscando emular imagens ou adotar novas soluções, tomando o registro, linguagem e disposição dos termos não como elementos naturais, acessórios ou inexpressivos do discurso, mas como peças-chave para a criação do sentido e da experiência poética - que faz parte desse mesmo sentido. Porém, em geral, mesmo quando falamos para nós mesmos que estamos diante de um poema, nós o lemos como se estivéssemos lidando com um texto em prosa. Destacar a poeticidade da tradução, tanto pela escolha que adoto quanto pela qualidade do texto original, não só é necessário protocolarmente, para justificar minha escolha dentro das várias opções tradutológicas, como também para nos lembrarmos que, ante o poema, devemos ter um papel ativo na leitura, devemos ter um novo olhar, dar tempo a cada verso, entrever o conceito remoto, estranhar a palavra conhecida, e buscar em nós mesmos certa sutileza para vermos o poético da poesia.

Portanto, cabe aqui um status quaestionis não exaustivo das traduções de Parmênides de modo a vermos a que tipo de proposta cada uma delas se filia. Inicialmente, para levantar alguns exemplos da língua portuguesa (que, de todo modo, é o que melhor podemos avaliar e mais nos interessa tradutologicamente), a versão de José Trindade Santos (2013), a mais difundida atualmente e de mais fácil acesso para ser adquirida, se presta como exemplo da "prosa recortada em versos", de teor muito alongado e pragmático, um exemplo claro de tradução escolar. A famosa tradução de Gerardo Mello Mourão (de 1986, recolhida no volume de Fernando Santoro, 2011), que se propõe poética, é, na realidade, um tanto prosaica e antissonora, a despeito de seu projeto e embora amparada em um registro lírico um tanto pomposo (o que pode dar a impressão de poesia). A própria tradução de Fernando Santoro (2011), por sua vez, retoma a ideia pedagógica de equivalência verso a verso, com algumas liberdades de expressão, porém sem qualquer pretensão métrica e, em certos trechos, com soluções controversas. Em um segundo momento, se recorremos a traduções em outras línguas, vemos uma mesma tendência à tradução de cunho prioritariamente escolar. Assim, a tradução de Jean Beaufret (1955) é acadêmica e em prosa, como o são as versões de Mario Untersteiner (1958), Leonardo Tarán (1965), Denis O’Brien (1987) e Richard McKirahan (2009). A tradução de David Galop (1991) segue o estilo verso a verso sem pretensões poéticas; em seu texto, a forma do poema serve apenas como elemento espelhar, para encontrarmos mais facilmente os termos no original. A mesma solução é adotada por Marcel Conche (1996), Giovanni Cerri (1999) e Giovani Reale (2001). É também o caso da tradução da ordem Āśram Vidyā, publicada sob o pseudônimo Raphael (2009), que repete o esquema verso a verso prosaico com um excesso de exposição no seio da própria tradução, ainda que isso seja útil para o entendimento de certas passagens. Já a proposta poética de Martin J. Henn (2003) é um pouco heterodoxa, pois propõe a modificação da ordem dos fragmentos tal qual estabelecida por Hermann Diels para trazer um "fluxo coerente de ideias e imagens" (p. 23), uma vez que o tradutor decide abordar a obra como um todo contínuo; complementarmente, os versos originais são vertidos para dísticos rimados, o que retorce um pouco o original de modo a extrair palavras suficientes para preencher a nova métrica 
e, além disso, sobrecarrega o texto com a criatividade do tradutor. Todos esses exemplos são apenas uma pequena parte ilustrativa das inúmeras edições do texto parmenidiano; outras tantas podem ser encaixadas em uma ou outra dessas soluções. Contudo, o que se vê é que o mais frequente é o texto de sabor acadêmico, com uma tradução funcional. Tirando dois dos exemplos aduzidos, a maior parte dos tradutores parece se preocupar menos com a poesia do poema do que com os "problemas" do poema, com o seu aspecto discursivo. Isso porque, em geral, a nossa formação é discursiva. As traduções escolares costumam se permitir alguns momentos de dicção poética e a ocorrência aqui e ali de alguma palavra ou construção atípica, porém esse elemento é incidental, não programático. ${ }^{2}$

No caso dos fragmentos de Parmênides, como temos originalmente um texto poético, e não unicamente expositivo no sentido da tradição filosófica que tem início em Aristóteles, considero haver um ganho em uma tradução também poética. É de se imaginar que o modo de escrita escolhido por Parmênides não teria sido apenas um capricho, mas um componente necessário de sua equação, o que é passível de não ser contemplado, caso o nosso foco seja uma abordagem mais conteudista. No fim das contas, o risco é acabarmos perdendo de vista alguma substância atualizável do texto (se é que ela de fato existe) em favor das palavras sobre o texto. ${ }^{3}$ A justificativa de buscar fazer uma tradução poética se funda nessa perspectiva de possibilitar um tipo diferente de experiência com relação ao que sobreviveu da obra. Embora possamos já estar acostumados com Parmênides, isso ocorre em geral por um ângulo relativamente prosaico: estamos acostumados com as ideias reportadas, com a interpretação de sua especulação, com o manejo instrumental de sua terminologia e estrutura discursiva (o proêmio, a via da verdade, a via da opinião). Proponho aqui apenas retornar ao texto original e experimentá-lo enquanto é: um poema. Tão somente o texto de Parmênides e os ecos de sua leitura individual, sem recorrer aos mais de dois mil anos de erudição que se impõem entre nós e os versos. Com frequência, ficamos um pouco mais interessados (e até mesmo perdidos) na bibliografia sobre um autor antigo, nas listas de estudos feitos sobre ele, do que na própria obra. Os comentários, a erudição, o trabalho expositivo são todos muito importantes porque nos revelam as faces de textos completamente distantes de nós, de modo que há muito que podemos negligenciar e diversos são nossos pontos cegos.

\footnotetext{
2 Tudo isso, claro, nos leva ao questionamento sobre o que seria a poesia ou mesmo o que torna uma tradução poética, o que evade muito o escopo dessa introdução. Alguns poucos elementos estruturais foram aludidos no início desta introdução, mas em caráter convencial, sem pretender destrinchar o que constitui a poesia em si.

${ }^{3}$ Recupero aqui a argumentação de Peter Kingsley (1999), que, inclusive, foi o que me levou a pensar em uma tradução poética para o texto apresentado. No mesmo caminho, vale sempre ter em mente as colocações feitas por Pierre Hadot (2016) a respeito da possibilidade de encontrarmos em alguns textos antigos a deixa para aquilo que ele chama de "exercícios espirituais", ou seja, aquilo que nos leva ao "encontro do posicionamento interior, da atitude concreta que [a mensagem do texto] implica" (p. 94). Em parte, estaria aí o atualizável de um texto antigo, depurado das causas e condições depuráveis, mas tendo sempre em vista o contexto histórico e o panorama conceitual em que a obra se situa.
} 
Mas o que de fato não podemos negligenciar, o que é mais importante é sempre a própria obra - e a nossa total atenção a ela.

Quanto aos meus critérios, apresento uma tradução dos hexâmetros para dodecassílabos alexandrinos, com cesura na sexta sílaba e tônicas na terceira e nona sílabas (e, evidentemente, na décima segunda). Alguns versos admitem mais de uma prosódia, mas dou preferência à leitura em anapestos (duas breves, uma longa). Sílabas átonas podem eventualmente ocupar a posição de uma tônica e serem lidas como tal. Como exemplo geral, veja-se o verso inicial dos fragmentos:

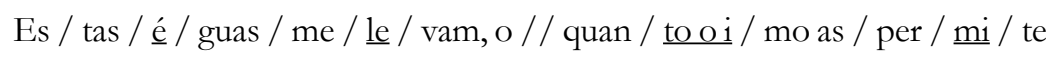

Evidentemente, enquanto há vantagens, esse tipo de escolha não vem também sem alguns sacrifícios. Para tornar mais fácil a consulta do leitor, trago antes de cada tradução o texto original grego, de modo que quem está familiarizado com a língua possa contrastá-lo com a minha versão e entender quais decisões tomei em cada passagem.

Noto ainda que, talvez por receio ou por automatismo, é comum ver alguns termos traduzidos seguindo sempre a sua acepção já canonizada, ou mesmo aquela que consta nas

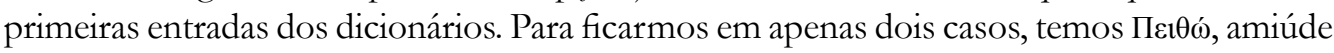

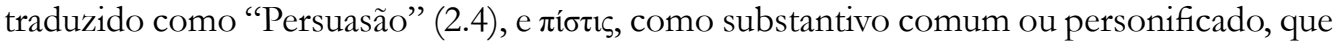
costuma ser vertido para "confiança" $(1.30 ; 8.12,28,50)$. No caso da obra em mãos, isso me parece, novamente, um equívoco mecânico. Considerado o contexto, esses termos me parecem um tanto padronizados e vazios de sentido, como se fossem uma lombada para a leitura do leitor e do tradutor. Parece-me também um vício de compreensão, por estarmos tão acostumados a enxergar esse vocabulário a partir de um registro retórico-oratório. Porém, a experiência filosófica oferecida por Parmênides é também (e, talvez, principalmente) de cunho religioso e revelatório: temos aqui uma viagem guiada por deusas; uma exposição cosmológica e epistemológica que a Deusa apresenta. Considero ser esse registro que deve ser levado em conta no momento da compreensão e tradução do texto. ${ }^{4}$ Não estamos lidando

\footnotetext{
${ }^{4} \mathrm{~A}$ ideia aqui é que uma experiência mais completa do poema envolve não apenas o filosófico, não apenas o religioso, não apenas o poético, mas os três elementos ao mesmo tempo, por serem interdependentes. É necessário articulá-los, apreciá-los como um todo na medida do possível. A leitura do poema se triangula por cada um desses itens e apenas dou aqui mais ênfase ao valor poético e religioso do texto por verificar que não costumamos contemplar essas duas instâncias na mesma proporção que contemplamos o argumento do poema, o seu itinerário discursivo. Se absolutizo o elemento filosófico, posso ser tachado de academicista. Se faço o mesmo com a religiosidade da obra, posso passar por esotérico. Se me concentro no poético, a alcunha é de beletrista. Agora, se, ao tentar contemplar os três ingredientes de uma só vez, a tradução recebe um desses estigmas, é evidente que a falha pode estar no desalinho entre a minha intenção e execução, o que é inevitável que aconteça em algum grau - a tradução é eternamente provisória -, mas, por vezes, o descompasso se dá entre o texto apresentado e a expectativa do leitor. Trata-se de um problema não só metodológico, como também de ordem subjetiva. O debate é fortuito e instigante, e se expande para muito além da obra de Parmênides.
} 
unicamente com uma mise en scène para justificar, pela autoridade do suposto contato com as divindades, sua teoria como mais verdadeira - inclusive, isso é, mais uma vez, um vício de leitura retórico, uma lente habitual que já se antecipa ao poema e toma um problema como já resolvido. Simultaneamente, caso contemplemos o uso retórico que é feito da experiência revelatória no poema, deveríamos então nos perguntar por que essa experiência é escolhida para veicular uma verdade. Nesse caso, teríamos que novamente nos debruçar sobre o elemento religioso, em vez de tomá-lo a valor de face. Retórica e religião não são fatores mutuamente excludentes, mas constantemente integrados. ${ }^{5}$

O essencial me parece ser o seguinte: Parmênides, filósofo-poeta, fala o que quer falar por meio da linguagem da experiência religiosa. ${ }^{6}$ Se quisermos de fato entrar no texto, talvez isso também deva protagonizar nosso olhar. Assim sendo, para retomar somente os

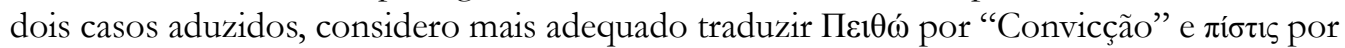
"fé", que melhor se coadunam às respectivas passagens e à natureza religiosa que parece guiar tanto a vivência retratada do Parmênides no poema quanto a elocução do poema de Parmênides.

No mais, sigo aqui a edição clássica dos fragmentos dessa obra e dos demais textos de autores pré-socráticos estabelecida por Herman Diels e Walther Kranz (1951).

\section{Fr. 1 B DK}

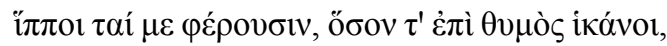

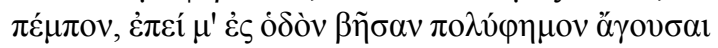

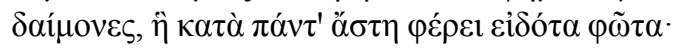

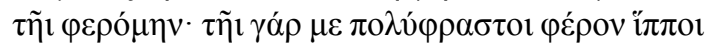

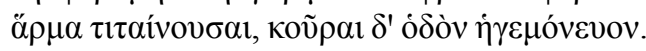

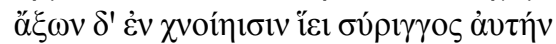

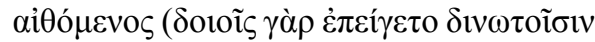

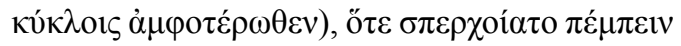

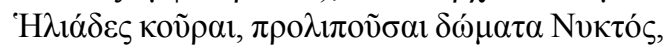

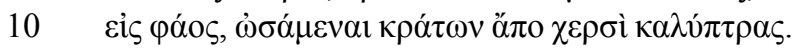

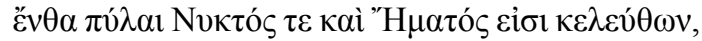

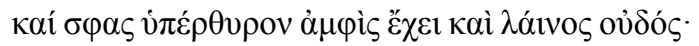

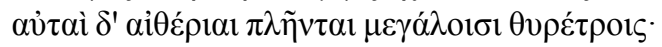

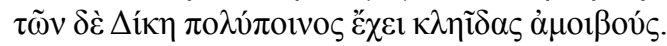

\footnotetext{
${ }^{5}$ Para um panorama geral sobre essa relação, cf. Pernot (2006).

${ }^{6}$ Como aponta Cerri (1999, p. 86-96), no fr. 1 B DK, por exemplo, a linguagem poética, concisa e não demonstrativa, se aproxima em Parmênides (assim como em outros filósofos do período arcaico) de um proferimento oracular, propriamente religioso, ao passo que em outro momento do seu poema, como o fr. 8 B DK, o poeta parece se vincular à tradição do epos que revelaria a condição do mundo, cujo modelo principal seria Hesíodo, além de outras teogonias contemporâneas ao filósofo, permitindo assim certo desenvolvimento expositivo que transita entre o filosófico (pela argumentação) e o religioso (por se tratar de uma revelação divina).
} 


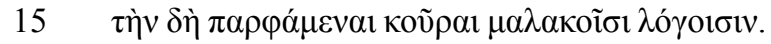

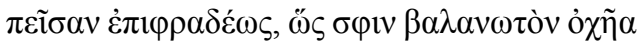

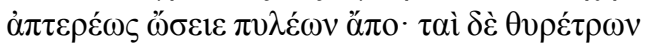

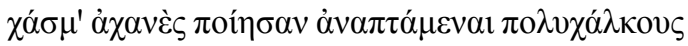

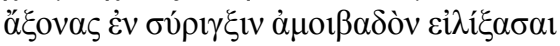

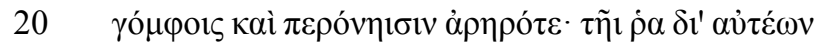

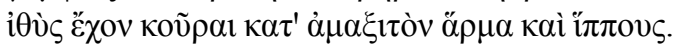

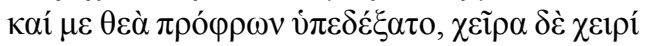

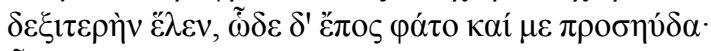

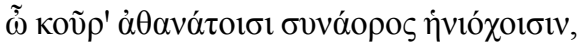

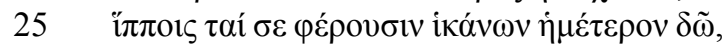

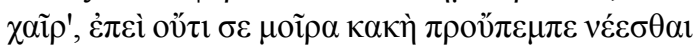

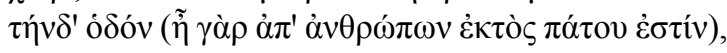

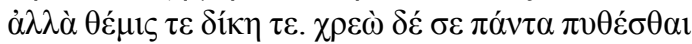

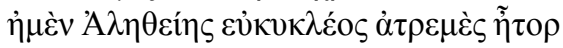

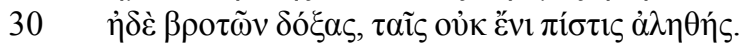

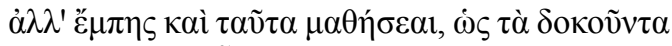

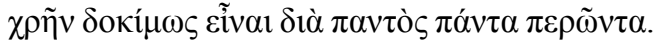

Estas éguas me levam o quanto o imo as permite e ora escoltam-me após o caminho egrégio da deidade que orienta os sábios nas urbes. Sou levado e p'ra lá vão as éguas instruídas,

5 a carruagem puxando, e à via guiam-me as jovens. Qual siringe, sibila o eixo nos cubos, escaldante, movido por ambas as rodas laterais rodopiando. Eis que avançam as jovens do Sol: levam-me, vindas dos lares da Noite

10 à luz e co' as mãos tiram do cimo os véus. Um portal parte as vias da Noite e do Dia, nele há um lintel e um pétreo umbral;

há portões colossais que o cerram, etéreo. A Justiça, o algoz, tem as chaves da troca.

15 Co' ela vão ter as jovens, com ternas palavras, instigando-a, atentas, que a barra tirasse do portal por um instante. E abriu os portões: fez-se um ávido abismo, espaçavam-se os cúpricos eixos e, um após o outro, giravam os quícios,

20 com cavilhas e pregos fixados. À trilha logo as ninfas vão, guiando as éguas e o carro. Acolheu minha mão com sua destra a deusa, tão propícia, e anunciou-me as seguintes palavras: "Ó tu jovem, consorte de imortais aurigas, 
25 tu que ao nosso lar vem, pelas éguas trazido: ora, alegra-te, não é vil sina que fez-te esta via cruzar, longe dos outros homens, mas a Lei e a Justiça. Tudo hás de aprender: o estável, circular coração da Verdade

30 e a mortal opinião, sem a fé verdadeira; também isto saber: como as aparências devem ser aceitadas; por tudo estão, todas.”

\section{Fr. 2 B DK}

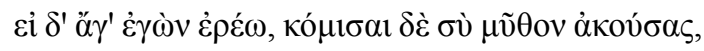

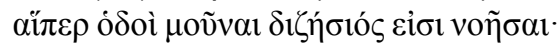

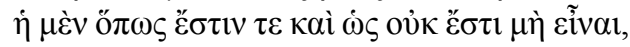

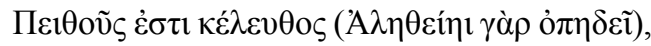

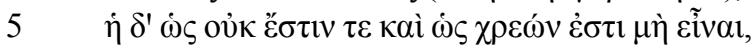

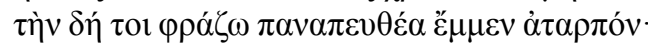

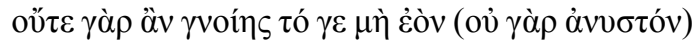
oű $\varepsilon \varepsilon \rho \alpha ́ \sigma \alpha 1 \zeta$.

Vem, direi, ouve tu e o relato acolhe! Eis as únicas vias de exame a pensar: a que há e jamais pode deixar de ser, trilha da Convicção, que a Verdade escolta;

5 e a que não é e nem sequer pode haver e te digo ela é uma rota insondável, é impossível saber sobre o que não é, nem se pode expressá-lo.

\section{Fr. 3 B DK}

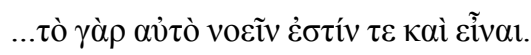

...pois o mesmo é o pensar e o ser.

\section{Fr. 4 B DK}

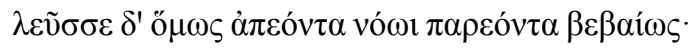

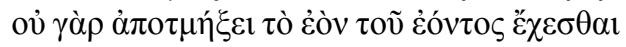

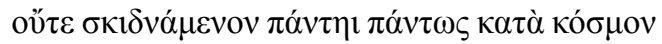

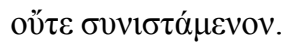

Vê que a mente faz, firme, o ausente presente. Pois não rompe ela o ser do que é próprio do ser: nem dispersa-o no cosmo, por todas as partes, nem sequer o congrega. 


\section{Fr. 5 B DK}

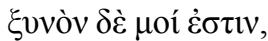

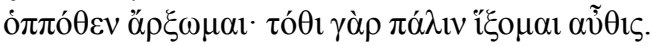

Indistinto p'ra mim

é por onde começo: aí chego de novo.

\section{Fr. 6 B DK}

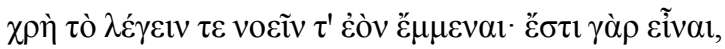

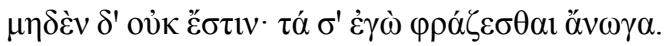

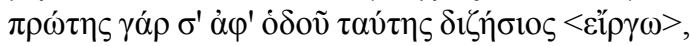

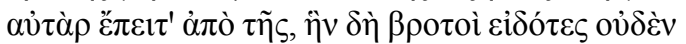

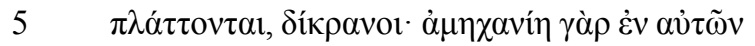

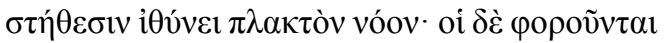

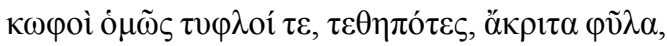

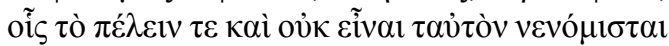

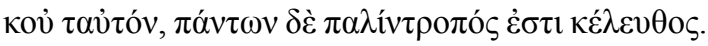

Há de haver o pensar, o dizer e o ser, pois o ser é e o nada, não. Peço que o peses.

Dessa primeira via de exame te afasto, mas também daquela outra em que os néscios mortais

5 deambulam com duas cabeças, guiadas suas mentes errantes pelo imo inepto.

Surda e cega, é levada a hesitante e confusa raça, crendo que o ser e o não ser são o mesmo e o não mesmo, e o caminho de tudo regride.

\section{Fr. 7 B DK}

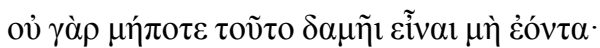

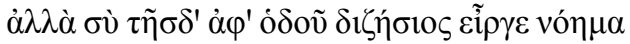

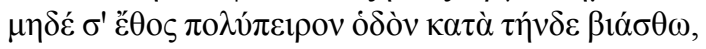

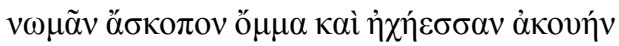

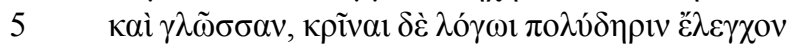
$\dot{\varepsilon} \xi \dot{\varepsilon} \mu \varepsilon \dot{\theta} \theta \varepsilon v \dot{\rho} \eta \theta \dot{\varepsilon} v \tau \alpha$.

Pois nunca há de se impor existência ao não ser.

Dessa via de exame afasta tua mente e que a praxe iterada não o coaja a essa via, desvirtuando os teus olhos incautos, tua língua

5 e tua escuta ruidosa. Arrazoa o teu tino sobre o o ób’ce que expus e de tantas porfias. 


\section{Fr. 8 B DK}

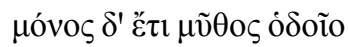

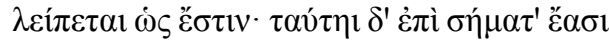

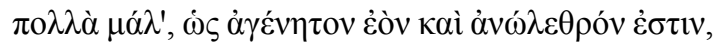

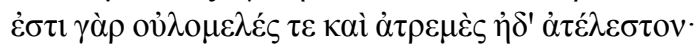

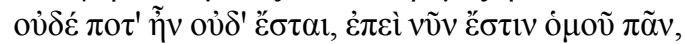

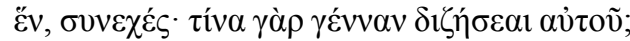

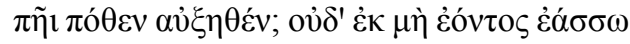

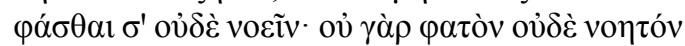

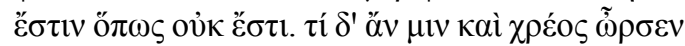

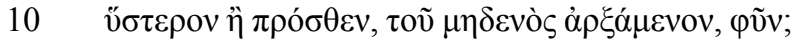

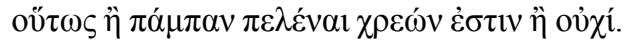

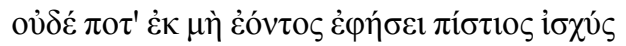

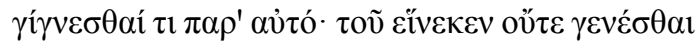

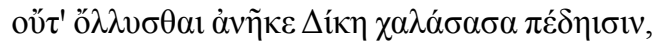

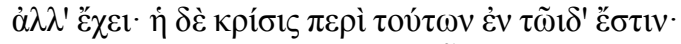

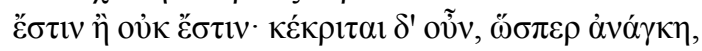

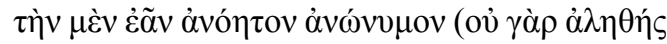

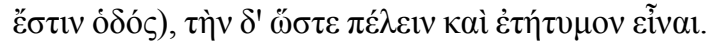

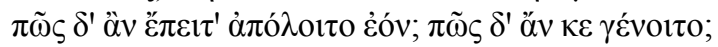

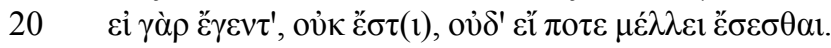

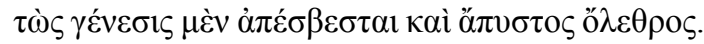

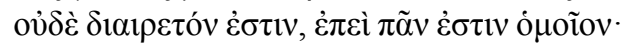

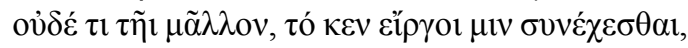

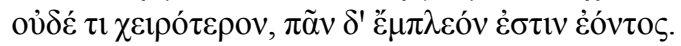

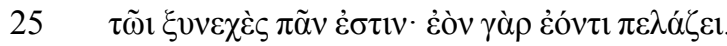

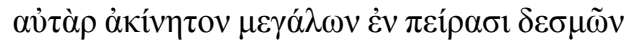

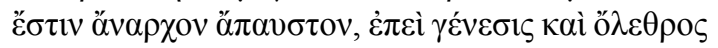

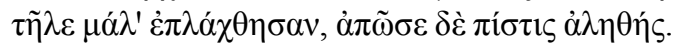

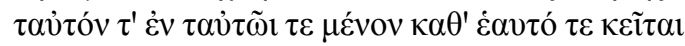

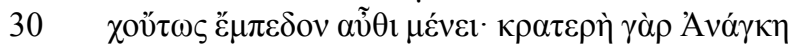

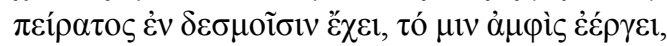

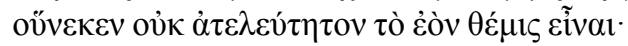

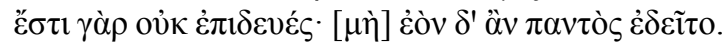

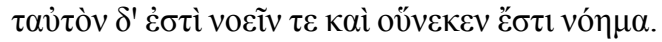

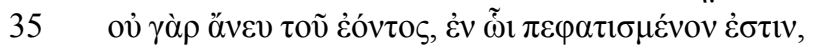

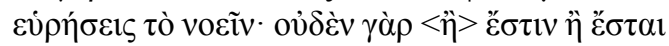

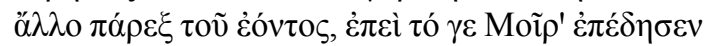

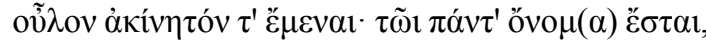

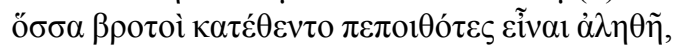

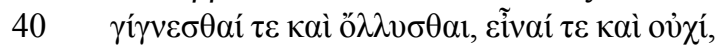

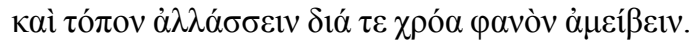

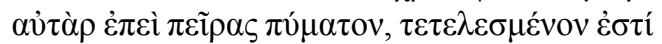

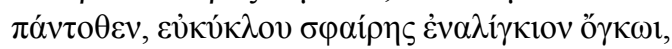

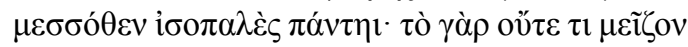




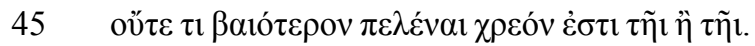

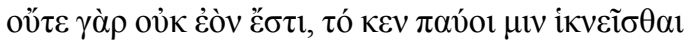

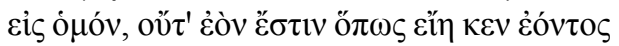

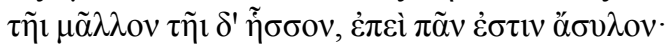

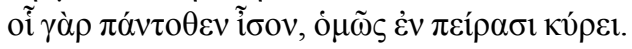

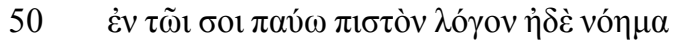

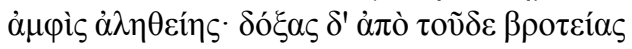

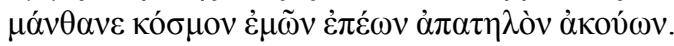

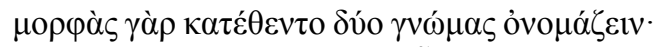

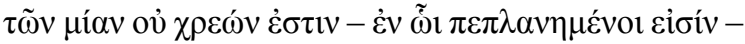

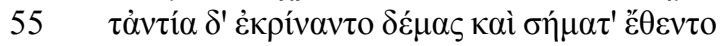

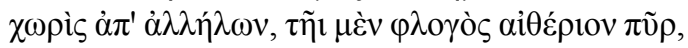

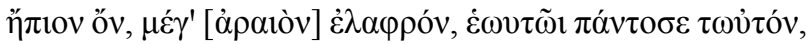

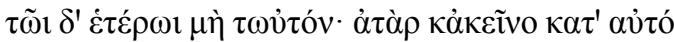

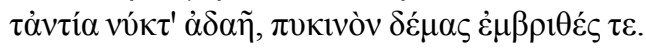

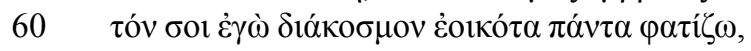

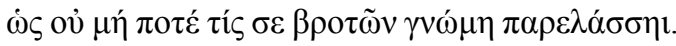

Resta só um relato

sobre a via que é. Há sinais nela, muitos, vários, de que o ser é incriado e indelével, pois completo é, imóvel e ainda infindo.

5 Nem já foi nem será; ora é, todo e coeso e contínuo e um. Que orto há p'ra apurar? Onde e como iria crescer? Pois te vedo a pensá-lo e exprimi-lo. Não se pensa ou fala do que não é. Forçou-o qual necessidade,

10 em tempo ido ou vindouro, a nascer desde o nada? Assim, deve algo ser totalmente ou nunca. E jamais o poder da Fé há de aprovar do ser vir o não ser. Logo, não permitiu-lhe nem surgir nem morrer a Justiça, lasseando

15 seus grilhões, mas contendo-os. Tal é o veredito: ou algo é ou não é. Julga, então, necessário desertar a impensável e anônima via, pois veraz não é, mas a outra é e é real. Como o ser poderia morrer ou nascer?

20 Pois, se era, não é ora, nem há de ser. Logo, some a origem e o ocaso é impreciso.

Nem mesmo é dividido; é um todo coeso.

Nada há que o exceda e a unidade cerceie.

Nem lhe há algo menor; o ser é um todo pleno. 
25 É um todo contínuo: o ser une-se ao ser.

É imóvel nos termos de seus vastos elos.

Sem princípio, sem fim, pois a origem e o ocaso

fora' expulsos p'ra longe co' a fé verdadeira.

Jaz tal é no que é, permanece qual é,

30 jaz em si firme assim, pois a Necessidade

poderosa o contém nos seus elos, que o cercam.

Logo, não seria lícito um ser inconcluso,

pois de nada carece ou carece de tudo.

Vale o mesmo ao pensar e à razão do pensar:

35 sem o ser, no qual ele seria expresso,

o pensar não verias. Pois nada mais é

nem será além do ser, já que a Sina o fixou

p'ra ser todo e imóvel. Logo, ele será

todo nome que os homens supõem ser real:

40 o nascer e o morrer, e o ser e o não ser, o local que se altera, e a cor nédia que muda.

Visto haver-lhe um limite extremo, é completo

e integral, qual a massa de cíclica esfera,

de seu centro ao seu todo há equivalência;

45 nem maior ou menor, cá ou lá, deve ser.

O não ser sequer pode impedir que o ser chegue

ao que é-lhe congênere; nem pode o ser

ser maior ou menor, cá ou lá: é um todo

homogêneo, inviolável, sito em seus limites.

50 Ao que cesso o discurso de fé e o pensar

relativo à verdade. Ora a humana opinião

compreende, ouve o erro na ordem do que expresso.

Duas formas julgaram que há e as batizaram,

das quais uma não é, e é nisso em que se perdem:

como um corpo, distingue' os contrários e impõem

marcas que os separa': a luz do fogo etéreo,

tão sutil, branda e a todos concorde consigo;

e, então, outra, distinta, um corpo contrário:

ei-la a Noite impérvia, em si densa e cerrada.

60 Plena e símil, narrei-te tal ordenação, p'ra que nenhuma crença mortal te desvie.

\section{Fr. 9 B DK}

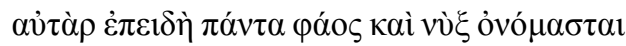

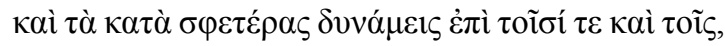

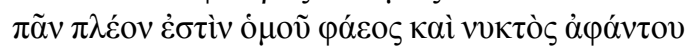

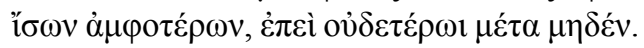


Porém, como a noite e a luz nomeiam tudo

e, afins às suas potências, estão cá e lá, tudo é pleno de luz e da noite escura igualmente e iguais, pois distantes do nada.

\section{Fr. 10 B DK}

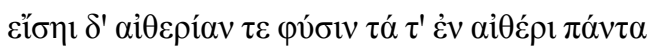

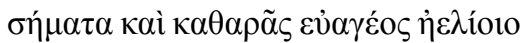

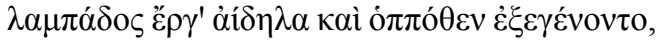

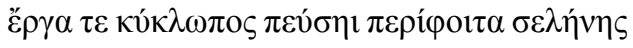

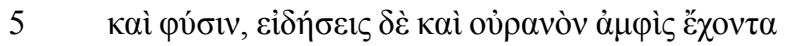

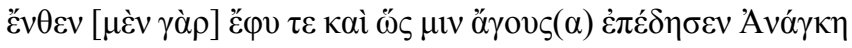

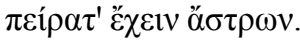

Verás a natureza etérea, e no éter toda e cada centelha, e as obras vorazes do impoluto e alvo lume solar, e sua origem. Saberás sobre as obras do olho lunar, 5 circular, sua natura; e o céu que os cinge, de onde vem, como a Necessidade o coage a cingir em seus termos os astros.

\section{Fr. 11 B DK}

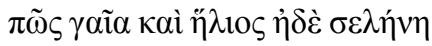

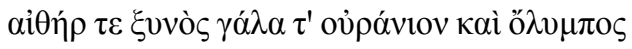

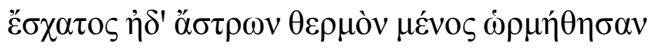

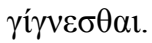

Como a terra, o sol, o éter comum, a Via Láctea celestial, como a lua e o Olimpo extremo e a força ardente dos astros surgiram, como foram assim impelidos.

\section{Fr. 12 B DK}

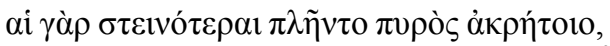

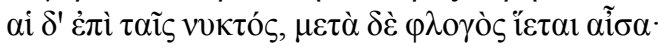

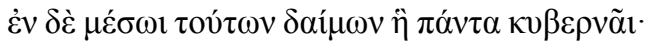

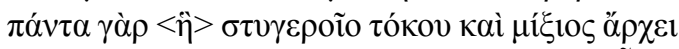

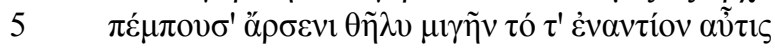

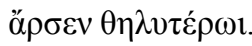


Os anéis mais estreitos de fogo impermisto plenos são; e os noturnos têm parte da chama.

E entre ambos há a deusa, que tudo governa: pois a tudo ela incita o parto árduo e a mistura, 5 leva ela a mesclar-se a fêmea co' o macho e, complementarmente, o macho co' a fêmea.

\section{Fr. 13 B DK}

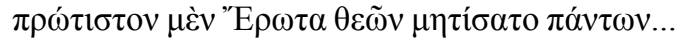

Dentre todos os deuses, criou antes Eros.

\section{Fr. 14 B DK}

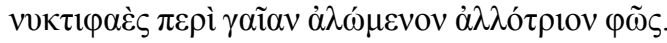

Noturnal lume à terra, ao qual falta outra luz.

\section{Fr. 15 B DK}

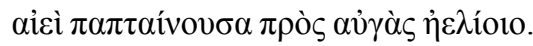

Ela sempre espreitando os raios do sol.

\section{Fr. 15a B DK}

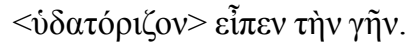

[E diz que a Terra] se enraíza na água.

\section{Fr. 16 B DK}

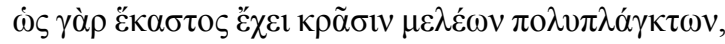

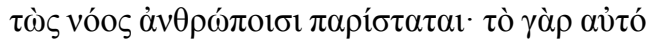

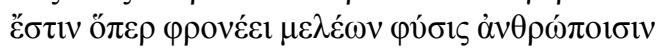

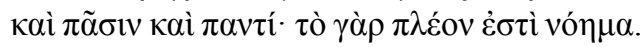

Como sempre articulam-se os membros errantes, tal a mente apresenta-se aos homens: é qual a nat'reza dos membros humanos que pensa sempre e em todos, pois plenitude é pensamento.

\section{Fr. 17 B DK}

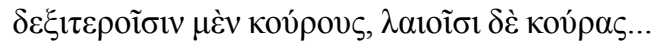

À direita os moços, à esquerda as moças. 


\section{Fr. 18 B DK}

femina virque simul Veneris cum germina miscent, venis informans diverso ex sanguine virtus temperiem servans bene condita corpora fingit. nam si virtutes permixto semine pugnent

5 nec faciant unam permixto in corpore, dirae nascentem gemino vexabunt semine sexum.

Se mulher e varão mescla' os sêmens de Vênus, $\mathrm{o}$ vigor feito às veias de sangues diversos forja corpos bem criados, caso haja equilíbrio. Se, permistos os sêmens, opõem-se os vigores

5 sem gerar unidade, permistos no corpo, vis, imolam co' sêmen dual o nato sexo.

\section{Fr. 19 B DK}

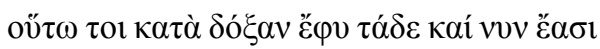

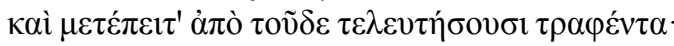

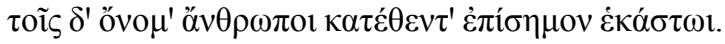

Assim, diz a opinião que tudo isso nasceu e ora é e, então, cresce p'ra, enfim, perecer, e os mortais dão a tudo nomes distintivos.

\section{REFERÊNCIAS}

BEAUfRET, J. Parménide. Le Poème. Paris: Presses Universitaires de France/Quadrige, 2006. 1 ed. de 1955.

DIELS, H.; KRANZ, W. (ed.). Die Fragmente der Vorsokratiker. Berlin: Weidmann, 1951. Repr. 1966.

HADOT, P. A filosofia como maneira de viver: entrevistas de Jeannie Carlier e Arnold I. Davidson. São Paulo: É Realizações, 2016.

HENN, M. J. Parmenides of Elea: a verse translation with interpretative essays and commentary to the text. Santa Barbara: Praeger, 2003.

KINGSLEY, P. In the dark places of wisdom. California: The Golden Sufi Center, 1999.

PARMENIDES. A text with translation, commentary, and critical essays by Leonardo Tarán. Princeton: Princeton University Press, 1965.

PARMÊNIDES. Da natureza. 3 ed. Tradução, notas e comentários de José Trindade Santos. São Paulo: Loyola, 2013. 
PARMÉNIDE. Le poème: fragments. Text grec, traduction, présentation et commentaire par Marcel Conche. Paris: Presses Universitaires de France, 1996.

PARMÉNIDE. Le poème de Parménide. Texte, traduction, essai critique par Denis O’Brien en collaboration avec Jean Frère pour la traduction française. Paris: J. Vrin, 1987.

PARMENIDES. On the order of nature. Edited by Raphael (Āśram Vidyā Order). New York: Aurea Vidyā, 2009.

PARMENIDE. Poema sulla natura. Introduzione, testo, traduzione e note di cura di Giovanni Cerri. Milano: Biblioteca Universale Rizzoli, 1999.

PARMENIDE. Sulla natura. Frammenti e testimonianze. Prefazione, introduzione, traduzione, note e parole chiave di Giovanni Reale. Milano: Bompiani, 2001.

PARMENIDE. Testimonianze e frammenti. Introduzione, traduzione e commento a cura di Mario Untersteiner. Millano: La Nuova Italia, Editrice Firenze, 1958.

PARMENIDES. The fragments of Parmenides: a critical text with introduction, translation, the ancient testimonia and a commentary by $A$. H. Coxon. Revised and expanded edition with new translations by Richard McKirahan and a new preface by Malcolm Schofield. Las Vegas: Parmenides Publishing, 2009.

PARMENIDES OF ELEA. Fragments. A text and translation with an introduction by David Gallop. Toronto: University of Toronto Press, 1991.

PARMÊNIDES; XENÓFANES. Filósofos épicos I: Parmênides e Xenófanes. Fragmentos. Edição do texto grego, tradução e comentários de Fernando Santoro. Rio de Janeiro: Hexis; Fundação Biblioteca Nacional, 2011.

PERNOT, L. The rhetoric of religion. Rhetorica, v. 24, n. 3, p. 235-54, 2006. 